\title{
Genome Analysis of a New Rhodothermaceae Strain Isolated from a Hot Spring
}

\begin{abstract}
Kian Mau Goh ${ }^{1 *}$, Kok-Gan Chan ${ }^{2}$, Soon Wee Lim ${ }^{1}$, Kok Jun Liew' ${ }^{1}$, Chia Sing Chan ${ }^{1}$, Mohd Shahir Shamsir ${ }^{1}$, Robson $\mathrm{Ee}^{2}$ and Tan-Guan-Sheng Adrian ${ }^{2}$
\end{abstract}

${ }^{1}$ Faculty of Biosciences and Medical Engineering, Universiti Teknologi Malaysia, Skudai, Malaysia, ${ }^{2}$ Division of Genetics and Molecular Biology, Institute of Biological Sciences, Faculty of Science, University of Malaya, Kuala Lumpur, Malaysia

A bacterial strain, designated RA, was isolated from water sample of a hot spring on Langkawi Island of Malaysia using marine agar. Strain RA is an aerophilic and thermophilic microorganism that grows optimally at $50-60^{\circ} \mathrm{C}$ and is capable of growing in marine broth containing $1-10 \%(\mathrm{w} / \mathrm{v}) \mathrm{NaCl}$. 16S rRNA gene sequence analysis demonstrated that this strain is most closely related ( $<90 \%$ sequence identity) to Rhodothermaceae, which currently comprises of six genera: Rhodothermus (two species), Salinibacter (three species), Salisaeta (one species), Rubricoccus (one species), Rubrivirga (one species), and Longimonas (one species). Notably, analysis of average nucleotide identity (ANI) values indicated that strain RA may represent the first member of a novel genus of Rhodothermaceae. The draft genome of strain RA is 4,616,094 bp with 3630 protein-coding gene sequences. Its GC content is $68.3 \%$, which is higher than that of most other genomes of Rhodothermaceae. Strain RA has genes for sulfate permease and arylsulfatase to withstand the high sulfur and sulfate contents of the hot spring. Putative genes encoding proteins involved in adaptation to osmotic stress were identified which encode proteins namely $\mathrm{Na}^{+} / \mathrm{H}^{+}$antiporters, a sodium/solute symporter, a sodium/glutamate symporter, trehalose synthase, malto-oligosyltrehalose synthase, choline-sulfatase, potassium uptake proteins (TrkA and TrkH), osmotically inducible protein $\mathrm{C}$, and the $\mathrm{K}^{+}$channel histidine kinase $\mathrm{KdpD}$. Furthermore, genome description of strain RA and comparative genome studies in relation to other related genera provide an overview of the uniqueness of this bacterium.

Keywords: Rhodothermaceae, Rhodothermus, Salinibacter, Salisaeta, strain RA, Rubricoccus, Rubrivirga, Longimonas

\section{INTRODUCTION}

The family Rhodothermaceae is placed under the order Cytophagales of the class Cytophagia within the phylum Bacteroidetes. At the time of writing, Rhodothermaceae consisted of six genera: Rhodothermus (Alfredsson et al., 1988; Marteinsson et al., 2010), Salinibacter (Antón et al., 2002; Makhdoumi-Kakhki et al., 2012), Salisaeta (Vaisman and Oren, 2009), Rubricoccus (Park et al., 2011), Rubrivirga (Park et al., 2013), and the recently described genus Longimonas (Xia et al., 2015). Rhodothermaceae is a family of gram-negative, non-sporulating, chemoorganotrophic aerobes shaped as rods or cocci, and most strains are pigmented (Park et al., 2014). 
Rhodothermus marinus was isolated from a submarine hot spring, at a depth of $2-3 \mathrm{~m}$ from the sea surface during low tide (Alfredsson et al., 1988), while Rhodothermus profundi was obtained from a deep-sea (2634 $\mathrm{m}$ depth) hydrothermal field (Marteinsson et al., 2010). Rhodothermus obamensis was initially described as a type strain of Rhodothermus (Sako et al., 1996) but was later regarded as a synonym of $R$. marinus owing to high $16 \mathrm{~S}$ rRNA gene sequence similarity, high DNA-DNA reassociation values, and similar fatty acid profiles (Silva et al., 2000). For $R$. marinus DSM $4252^{\mathrm{T}}$ (Nolan et al., 2009) complete genome is available in GenBank (CP001807). The genome of the sister strain R. marinus SG0.5JP17-172 (CP003029) is also available but has not been published. Draft genomes have been deposited for the other strains of Rhodothermus, which include R. profundi DSM $22212^{\mathrm{T}}$ (BioProject ID: PRJNA303571), $R$. marinus JCM $9785^{\mathrm{T}}$ (PRJDB841), and R. marinus SG0.5JP17-171 (PRJNA52953).

Members of the genus Salinibacter (Salinibacter iranicus, Salinibacter luteus, and Salinibacter ruber) were isolated from a hypersaline evaporating water body (Park et al., 2014). S. ruber requires a high salt concentration, exhibiting optimum growth in media with $15-25 \%(w / v)$ total salts (Antón et al., 2002). In addition, sodium chloride and magnesium chloride are vital for the growth of $S$. ruber (Antón et al., 2002). The complete genome of S. ruber DSM $13855^{\mathrm{T}}$ (CP000159.1) has been assembled into one contig of $3,386,737 \mathrm{bp}$, while the genome of $S$. ruber M8 (PRJNA48827) is available in draft form. A species of another genus, the long, rod-shaped bacterium Salisaeta longa S4-4 ${ }^{\mathrm{T}}$ (= DSM 21114 ${ }^{\mathrm{T}}$; ATTH00000000.1), was isolated from hypersaline water bodies formed from premixed Dead Sea and Red Sea water samples (Vaisman and Oren, 2009). Although few studies have been conducted on strain S4-4 ${ }^{\mathrm{T}}$, its genome has been sequenced under the Community Science Program of the Joint Genome Institute (Project ID: 404303).

Rubricoccus marinus $\mathrm{SG}-29^{\mathrm{T}}$, a reddish, coccal bacterium isolated from shallow water of the North Pacific Ocean, is the type strain of the type species of Rubricoccus (Park et al., 2011). The average GC content of strain SG-29 $9^{\mathrm{T}}(68.9 \mathrm{~mol} \%$, determined by HPLC) is the highest value known for Rhodothermaceae. Two years after the report of Rubricoccus marinus, the same group of researchers isolated another bacterium from deep seawater of the western North Pacific Ocean. They proposed a new genus, Rubrivirga, with Rubrivirga marina SAORIC- $28^{\mathrm{T}}$ as the sole species (Park et al., 2013). Recently, a new genus of Rhodothermaceae, Longimonas, was proposed (Xia et al., 2015). Longimonas halophila SYD6 ${ }^{\mathrm{T}}$ was obtained from a marine solar saltern on the coast of Weihai, China (Xia et al., 2015). The 16S rRNA gene sequence similarity between L. halophila SYD6 ${ }^{\mathrm{T}}$ and S. longa is less than 92\% (Xia et al., 2015). Like most other strains of Rhodothermaceae, strain $\mathrm{SYD6}^{\mathrm{T}}$ is red. At the time of writing, genome information for Rubricoccus, Rubrivirga, and Longimonas were not available.

Among the six aforementioned genera, Rhodothermus and Salinibacter are better studied (Mongodin et al., 2005; Peña et al., 2005, 2010; Rosselló-Mora et al., 2008; Oren, 2013; Oren et al., 2016). Because most Rhodothermus spp. can grow optimally at $65^{\circ} \mathrm{C}$, numerous attempts to mine and examine thermostable proteins from this genus have been reported. Examples of these enzymes include amylase and pullulanase (Gomes et al., 2003), $\alpha$-L-arabinofuranosidase (Gomes et al., 2000), cellulase (Okano et al., 2014), cellobiose 2-epimerase (Ojima et al., 2011), chitinase (Hobel et al., 2005), and $\alpha$-galactosidase (Blücher et al., 2000).

In this work, a bacterium designated as strain RA was isolated from a saline hot spring sample. Analyses of the genome, 16S rRNA gene, and housekeeping gene sequences suggested that the strain could represent a new genus of Rhodothermaceae. The purpose of this report is to describe the phenotypic characteristics of this strain and present its genome sequence.

\section{MATERIALS AND METHODS}

\section{Water Sample Analyses and Bacterial Characterization}

Three water samples were collected from a hot spring near the village of Ayer Hangat $\left(6^{\circ} 25^{\prime} 22^{\prime \prime} \mathrm{N}, 99^{\circ} 48^{\prime} 49^{\prime \prime} \mathrm{E}\right)$ and analyzed by Allied Chemists Laboratory Sdn. Bhd. (Malaysia) within 3 days of sampling, in accordance with American Public Health Association and United States Environmental Protection Agency guidelines.

Marine agar (Conda, Torrejón de Ardoz Madrid, Spain) was adjusted to $\mathrm{pH} 7.6$ with $3 \mathrm{M} \mathrm{NaOH}$. A $100 \mu \mathrm{L}$ aliquot of a water sample was spread on the agar and incubated at $50^{\circ} \mathrm{C}$. After 2 days of incubation, several colonies appeared on the agar. Three distinct colonies were repeatedly streaked on the same medium to obtain pure colonies as confirmed by a single morphology and size when examined directly using a DM300 light microscope (Leica Microsystems, Germany). 16S rRNA gene sequences of these isolates were amplified using the forward primer $27 \mathrm{~F}$ (5'-AGAGTTTGATCMTGGCTCAG-3') and the reverse primer 1525R (5'-AAGGAGGTGWTCCARCC-3') (Lane, 1991; Chai et al., 2012). Sequencing was performed at Malaysian First BASE service provider.

The isolated strains were Gram stained and then examined under a Leica DM300 light microscope. For investigation of endospore formation, endospore staining was conducted on bacterial colony obtained from a fresh culture plate as well as a week-old culture (Schaeffer and Fulton, 1933). The growth temperature range of strain RA was assessed by growing this bacterium in marine broth and were incubated at $4,10,37,45$, $50,55,60,65,70$, and $75^{\circ} \mathrm{C}$ for up to 3 days. To determine the optimal $\mathrm{pH}$ which support the growth of this bacterium, strain RA was grown in non-buffered marine broths with various $\mathrm{pH}$-values ( $\mathrm{pH} 3.0-12$ with interval $\mathrm{pH}$-value of 0.5 ). The salt tolerance of strain RA was determined in marine broth [2\% $(\mathrm{w} / \mathrm{v}) \mathrm{NaCl}]$ and half-strength marine broth [1\% (w/v) $\mathrm{NaCl}]$, at increments of $1.0 \%(\mathrm{w} / \mathrm{v})$ up to $20 \% \mathrm{w} / \mathrm{v}$.

Carbohydrate utilization for strain RA was measured using API 50CHB/E test strips (bioMe'rieux, Marcy-l'Étoile, France). Catalase activity and oxidase activity were determined as described by Cowan and Steel (1965). Motility of strain RA was determined using semi-solid medium and bacterial cells were inoculated with a straight wire making a single stab down the center of the tube to about half the depth of the medium, followed by incubation at $50^{\circ} \mathrm{C}$ and were 
examined for up to 3 days. Susceptibility to different antibiotics was determined by the disc diffusion method (Kirby-Bauer antibiotic testing) on marine agar at $50^{\circ} \mathrm{C}$. Bacterial lawns were prepared by spreading the cells on plates with sterile cotton swabs dipped in colony suspensions adjusted to a 2.0 McFarland standard. The following antibiotics were tested: ampicillin, bacitracin, chloramphenicol, erythromycin, gentamicin, kanamycin, nalidixic acid, ciprofloxacin, colistin, penicillin, rifampicin, sulfamethoxazole, and vancomycin.

\section{DNA Purification}

Cells were scraped from marine agar plates and subjected to genomic DNA extraction using a Qiagen DNeasy Blood and Tissue Kit (Qiagen, Venlo, Netherlands), according to the manufacturer's instructions. A NanoDrop 1000 spectrophotometer (Thermo Scientific, Wilmington, DE, USA) was used to determine the purity $\left(\mathrm{A}_{260} / \mathrm{A}_{280}\right.$ ratio $)$ and concentration of the DNA, which were 1.98 and $1400 \mathrm{ng} \mu \mathrm{L}^{-1}$, respectively.

\section{Genome Sequencing and Annotation}

Whole-genome sequencing libraries were prepared using a Nextera DNA Sample Preparation Kit according to the manufacturer's guidelines (Illumina, Inc., San Diego, CA, USA). Paired-end $(2 \times 100 \mathrm{bp})$ sequencing was performed on the HiSeq 2500 platform using the HiSeq Rapid SBS Kit v2 (Illumina, Inc., San Diego, CA, USA). Adapter sequence removal, quality trimming, and de novo genome assembly were conducted using CLC Genomics Workbench version 7.5 (CLC Bio, Aarhus, Denmark). The resulting sequences were then annotated with NCBI Prokaryotic Genome Annotation Pipeline version 2.10, using the "best-placed reference protein set" method, and GeneMarkS+ version 3.1, which integrates information regarding protein alignments, frameshifted genes, non-coding RNA sequences, and DNA-specific statistical patterns typical of protein-coding and non-coding regions into gene predictions (Besemer and Borodovsky, 2005). Annotation and KEGG pathway prediction for strain RA were performed using the online service Pathosystems Resource Integration Center (PATRIC; Mao et al., 2015) as well as Integrated Microbial Genomes/Expert Review (IMG/ER; Markowitz et al., 2009). VirulenceFinder version 1.5 (threshold 85\%, minimum length $60 \%$; Joensen et al., 2014) and ResFinder version 2.1 (threshold $60 \%$, minimum length 60\%; Zankari et al., 2012) were used to predict the presence of putative virulence factors and antimicrobial resistance genes, respectively.

The following genomes were downloaded from GenBank: Rhodothermus marinus DSM 4252 ${ }^{\mathrm{T}}$ (CP001807.1), S. ruber DSM $13855^{\mathrm{T}} \quad$ (CP000159.1), and S. longa DSM $21114^{\mathrm{T}}$ (ATTH00000000.1). Genome comparisons were performed using the average nucleotide identity (ANI) function of IMG/ER. The complete 16S rRNA gene sequence of strain RA was submitted to GenBank under accession number KU517707.

\section{Phylogenetic Analysis}

The 16S rRNA gene sequences phylogenetic tree was constructed using Neighbor-joining method with 1000 bootstrap replicates.
All the methods above were conducted using Molecular Evolutionary Genetics Analysis software (MEGA, Version 6.0; Tamura et al., 2013).

\section{Data Access}

Sequencing data for strain RA are available online as BioProject PRJNA308615, NCBI taxonomy ID 1779382, Patric genome id 1100069.3, and IMG/ER Taxon ID 2648501586 (GOLD ID Gs0118059). This Whole Genome Shotgun project has been deposited at DDBJ/EMBL/GenBank under the accession number LRDG00000000. The version described in this paper is version LRDG01000000. A Fasta file of the strain RA genome is available in the following figshare link (https:/figshare. com/s/60cla70599d11684aaf7). All Supplementary Materials are available in figshare.

\section{RESULTS AND DISCUSSION}

\section{Site Description}

The hot spring sampled in this study is located near Ayer Hangat (AH) on Langkawi Island, Malaysia. Owing to its relatively low temperature $\left(\sim 45^{\circ} \mathrm{C}\right)$, the hot spring has been used for balneotherapy for tourists and local residents. The water in this hot spring is trapped within a man-made pit and is therefore nearly stagnant and is slightly yellowish, and there is a thin biomat $(<1 \mathrm{~cm})$ on the sides of the pit that is light brown, green, and yellow. Water samples taken from this site contained high concentrations of $\mathrm{Na}^{+}\left(7900 \mathrm{mg} \mathrm{L}^{-1}\right), \mathrm{Cl}^{-}\left(13,800 \mathrm{mg} \mathrm{L}^{-1}\right)$, $\mathrm{Mg}^{2+}\left(390 \mathrm{mg} \mathrm{L}^{-1}\right), \mathrm{SO}_{4}^{2-}\left(950 \mathrm{mg} \mathrm{L}^{-1}\right), \mathrm{S}\left(480 \mathrm{mg} \mathrm{L}^{-1}\right)$, and $\mathrm{CaCO}_{3}\left(5020 \mathrm{mg} \mathrm{L}^{-1}\right)$.

\section{Cell Morphology and Biochemical Analyses}

Three bacteria (designated as strains RA, RB, and RC) were isolated from a water sample taken at the $\mathrm{AH}$ hot spring. Based on 16S rRNA gene sequences, strains RB and RC had the closest match with Bacillus spp. and Geobacillus spp., respectively. Since strain RA had low sequence similarity to known Rhodothermaceae (see below), it was selected for subsequent analyses. The strain RA colonies appeared smooth, mucoid, and raised, with $\sim 1 \mathrm{~mm}$ margins. Furthermore, while the majority of Rhodothermaceae strains form orange-reddish colonies (Park et al., 2014), the colonies of strain RA were cream colored (Table 1). Meanwhile, light microscopy analysis demonstrated that this isolate is a gram-negative, rod-shaped bacterium that can be arranged in pairs and chains or as lone cells. Rhodothermus spp. are known to occur singly, but not in chains or filaments (Park et al., 2014). Strain RA was motile and catalase positive and it grew well in marine broth and half-strength marine broth but failed to grow on Luria-Bertani, Reasoner's 2A, Mueller-Hinton, or nutrient agar, with or without supplementation with $2 \%(\mathrm{w} / \mathrm{v}) \mathrm{NaCl}$. While the microorganism grew at $37-60^{\circ} \mathrm{C}$ and $\mathrm{pH} 5.0-9.0$, optimal growth occurred at $50-60^{\circ} \mathrm{C}$ and under circumneutral conditions. Strain RA was unable to grow at $65^{\circ} \mathrm{C}$. Furthermore, strain RA exhibited growth in marine broth supplemented with $1-10 \%(w / v) ~ \mathrm{NaCl}$. On marine agar, strain RA was susceptible to erythromycin (zone of inhibition of $25 \mathrm{~mm}$ around a $5 \mu \mathrm{g}$ disc), rifampicin (25 mm 
TABLE 1 | General features and information regarding the sequencing of the strain RA genome, according to the MIGS (Minimum information about a genome sequence) recommendations.

\begin{tabular}{|c|c|}
\hline Items & Description \\
\hline \multicolumn{2}{|l|}{ GENERAL FEATURES } \\
\hline Gram stain & Negative \\
\hline Cell shape & Rod \\
\hline Pigmentation & Cream \\
\hline Motility & Motile \\
\hline Temperature range; optimum & $37-60^{\circ} \mathrm{C} ; 50-60^{\circ} \mathrm{C}$ \\
\hline Salinity range; optimum & $1-10.0 \% \mathrm{NaCl}(\mathrm{w} / \mathrm{v}) ; 1-5 \% \mathrm{NaCl}(\mathrm{w} / \mathrm{v})$ \\
\hline pH range; optimum & $5.0-9.0 ; 7.6$ \\
\hline Carbon source & Varied \\
\hline \multicolumn{2}{|l|}{ MIGS 4.0 DATA } \\
\hline Submitted_to_insdc & GenBank \\
\hline investigation_type & bacteria_archaea \\
\hline project_name & $\begin{array}{l}\text { Rhodothermaceae bacterium RA genome } \\
\text { sequencing }\end{array}$ \\
\hline experimental_factor & NA \\
\hline lat_lon & NA \\
\hline Depth & NA \\
\hline geo_loc_name & Langkawi, Malaysia \\
\hline collection_date & $2014-10-10$ \\
\hline env_biome & Hot spring \\
\hline env_feature & Water \\
\hline env_material & Water with high $\mathrm{NaCl}$ content \\
\hline env_package & Missing \\
\hline num_replicons & NA \\
\hline ref_biomaterial & NA \\
\hline source_mat_id & NA \\
\hline Pathogenicity & NA \\
\hline biotic_relationship & Free-living \\
\hline trophic_level & Chemoheterotroph \\
\hline rel_to_oxygen & Aerobic \\
\hline isol_growth_condt & Marine agar, $\mathrm{pH} 7.6,50^{\circ} \mathrm{C}$ \\
\hline \multicolumn{2}{|l|}{ GENOME ASSEMBLY DATA } \\
\hline assembly_name & CLC bio CLC Genomics Workbench version 7.5 \\
\hline finishing_strategy & $\begin{array}{l}\text { De novo assembly to high quality draft; } 121 \text {-fold } \\
\text { coverage }\end{array}$ \\
\hline sequencing Technology & HiSeq 2500 \\
\hline
\end{tabular}

zone around a $5 \mu \mathrm{g}$ disc), and penicillin ( $35 \mathrm{~mm}$ zone around a $10 \mathrm{U}$ disc). Lastly, like R. marinus DSM $4252^{\mathrm{T}}$, strain RA is a non-spore-forming bacterium.

\section{Phylogenetic Relationships}

For phylogenetic analysis of strain RA, we sequenced the entire $16 \mathrm{~S}$ rRNA coding region (1516 bp) of the microorganism and compared the resulting sequence against the GenBank and EzTaxon-e databases (Kim et al., 2012). These analyses indicated that the closest relative (99\% identity, $98 \%$ coverage) of strain RA is the uncultured bacterial metagenome clone KSB113 (JX047086), which was identified in a marine hot spring at Kalianda Island, Indonesia (unpublished report). Moreover, the genera closest to strain RA (86.5-89.3\%) are those of the family Rhodothermaceae: Rhodothermus (Alfredsson et al., 1988; Sako et al., 1996; Marteinsson et al., 2010), Salinibacter (Antón et al., 2002; Makhdoumi-Kakhki et al., 2012), Salisaeta (Vaisman and Oren, 2009), Rubricoccus (Park et al., 2011), Rubrivirga (Park et al., 2013), and Longimonas (Xia et al., 2015; Table 2, Figure 1). The sequence identities of housekeeping genes of strain RA and species of the family Rhodothermaceae are also low, for instance (i) $r e c A, 83 \%$ to $R$. marinus DSM $4252^{\mathrm{T}}$; (ii) $r p o D, 85 \%$ to $R$. marinus DSM $4252^{\mathrm{T}}$ and $82 \%$ to S. ruber DSM $13855^{\mathrm{T}}$; and (iii) gyrB, $79 \%$ to $R$. marinus DSM $4252^{\mathrm{T}}$ and $79 \%$ to $S$. ruber DSM $13855^{\mathrm{T}}$.

We then compared the available genome sequences of several of these strains with the draft genome of strain RA (Table 2). In addition to exhibiting low $16 \mathrm{~S}$ rRNA gene sequence identity (89.3\%), strain RA and R. marinus DSM $4252^{\mathrm{T}}$ had a low average ANI-value of 73.28 (Table 2). The ANI-value between strain RA and $R$. marinus SG0.5JP17-171 or R. marinus SG0.5JP17-172 was 73.23 , while that between strain RA and $R$. profundi DSM $22212^{\mathrm{T}}$ was 70.66 . Meanwhile, the average ANI-values for strain RA when compared with S. ruber DSM $13855^{\mathrm{T}}$ and S. longa DSM $21114^{\mathrm{T}}$ were 71.85 and 71.47 , respectively. Collectively, these data strongly suggest that strain RA is a novel strain of Rhodothermaceae.

\section{Genomic Features of Strain RA}

The draft genome of strain RA is 4,616,094 bp in length (Table 3), and the largest contig is $819,789 \mathrm{bp}$. The N75, N50, and N25-values are $89,274,152,113$, and $242,570 \mathrm{bp}$, respectively. The average coverage for the 91 contigs obtained was 120fold. Notably, the genome of strain RA is larger than those of Rhodothermus marinus (3.3 Mbp), S. ruber (3.5-3.8 Mbp), and S. longa (3.1 Mbp; a draft genome with three contigs; Table 2). Furthermore, the genome is predicted to contain 3680 coding DNA sequences (CDS) and 50 rRNA genes, and it has an average GC content of $68.28 \%$, which is markedly higher than that of $R$. marinus DSM $4252^{\mathrm{T}}$ (64.3\%; Nolan et al., 2009), S. ruber DSM $13855^{\mathrm{T}}$ (66.2\%; Mongodin et al., 2005), and S. longa DSM $21114^{\mathrm{T}}$ (63.5\%) but comparable to that of R. marinus KCTC $23197^{\mathrm{T}}$ (68.9\%; Table 2). Among the CDS, the functions of 2815 (76.49\%) sequences could be predicted, while $879(24.38 \%)$ of the total CDS are annotated as enzymes. Protein-coding genes related to clusters of orthologous groups (COGs) are shown in Figure 2.

Using the Phylogenetic Distribution of Genes function in IMG/ER, we determined the best hits for protein-coding genes in strain RA at a 60\% identity cutoff. A total of 1408 genes (39\% of the protein-coding genes) were found to be similar to genes in the phylum Bacteroidetes. The majority of these sequences are affiliated with class Cytophagia and unclassified classes, while only 52 genes are related to Bacteroidia, Flavobacteriia, and Sphingobacteriia. Table S1 shows that 1987 genes (54.7\% of the protein-coding genes) were not assigned to any phylum, as they are specific to strain RA. When all protein-coding genes were examined at a 90\% sequence identity threshold, 99.75\% (3621) of the genes were classified as unassigned. This suggests that the gene sequences of strain RA are more diverse than those of its Rhodothermaceae counterparts (data not shown). 
Gob et al.

Rhodothermaceae Strain RA Genome

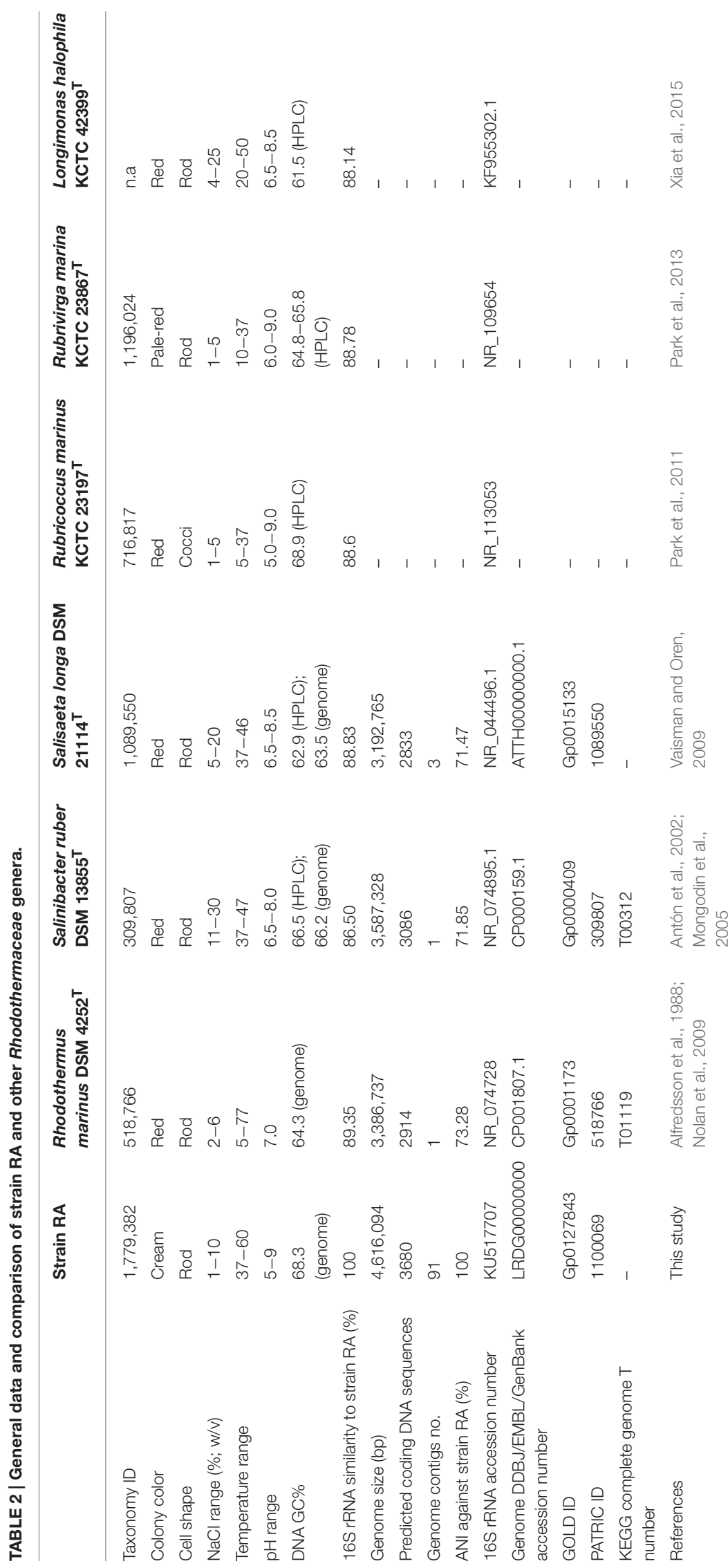

Frontiers in Microbiology | www.frontiersin.org

5

July 2016 | Volume 7 | Article 1109 


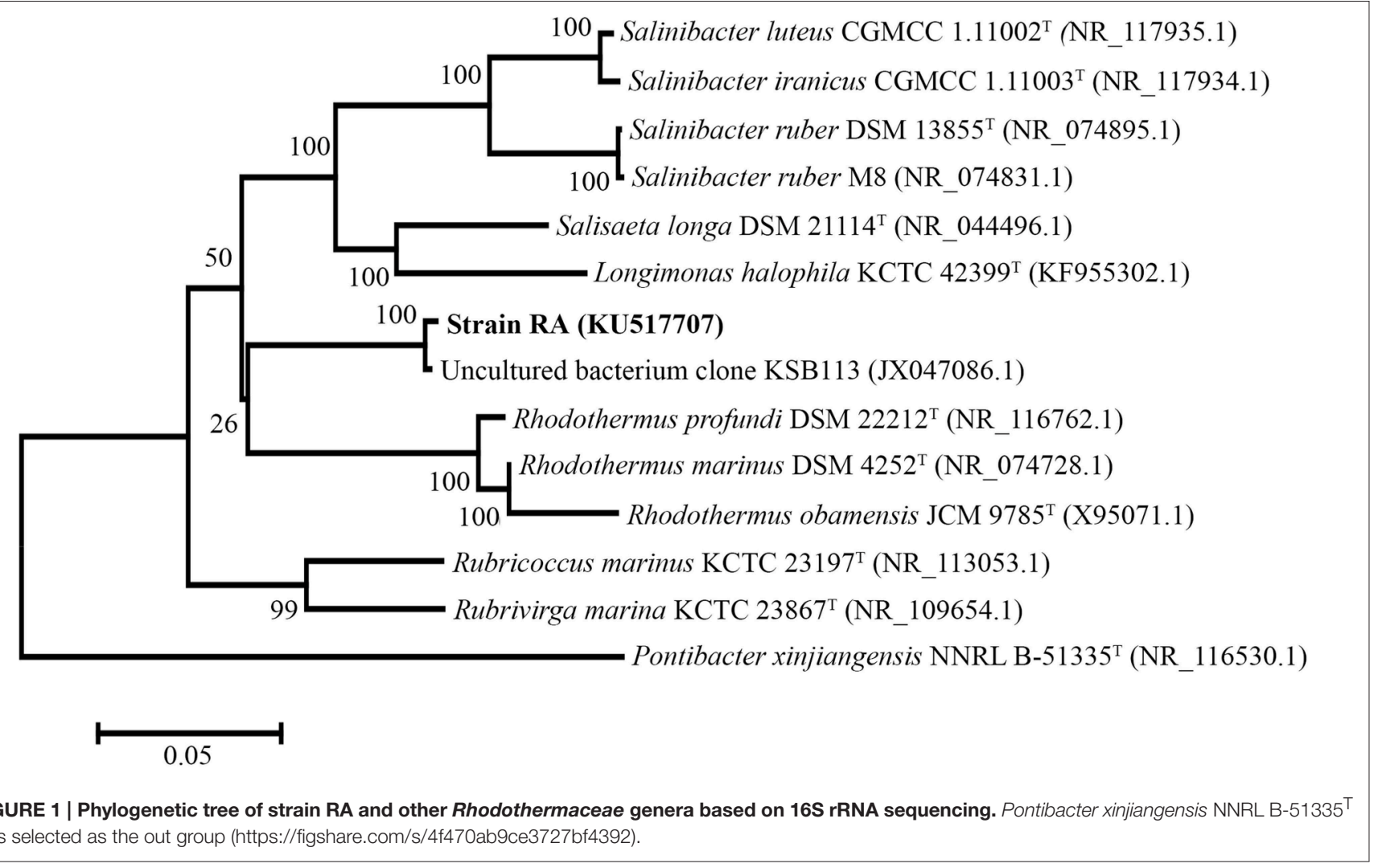

Consistent with its observed motility, strain RA carries the genes necessary for complete flagellum assembly. Furthermore, genomic analysis using the antiSMASH predictor program (Blin et al., 2013) identified a gene cluster encoding a type III polyketide synthase. The key enzyme within this cluster has a structural domain related to chalcone synthase; thus, strain RA might use this enzyme to produce certain types of aromatic ketones, including chalcones, which possess important properties for industrial use (Singh et al., 2014).

\section{Comparison of the Genome of Strain RA with those of Other Rhodothermaceae Strains}

At the time of writing, the genomes of three $R$. marinus strains and two $S$. ruber strains, as well as the draft genome of $S$. longa DSM $21114^{\mathrm{T}}$, were publicly available. Unless otherwise specified, we chose to compare the genome of strain RA with the complete genome sequences of R. marinus DSM $4252^{\mathrm{T}}$ and S. ruber DSM $13855^{\mathrm{T}}$.

RAST analysis identified 215 and 221 strain RA genes that are not carried by $R$. marinus DSM $4252^{\mathrm{T}}$ and $S$. ruber DSM $13855^{\mathrm{T}}$, respectively (Table S2), including genes encoding DnaK-related proteins, cytochrome C oxidase subunit CcoN, superfamily II DNA/RNA helicases (SNF2 family), primosomal protein $\mathrm{N}^{\prime}$ (replication factor $\mathrm{Y}$ ) superfamily II helicase, $\beta$-ureidopropionase, fucose permease, gluconolactonase, $\quad \alpha$-L-fucosidase, malto-oligosyltrehalose synthase, $\alpha$-1,2-mannosidase, endo-1,4- $\beta$-xylanase, endogluc anase, choline-sulfatase, putrescine transport ATP-binding protein PotA, arylsulfatase, and sulfate permease. Of these, strain RA likely maintains the genes for sulfate permease and arylsulfatase to withstand the high sulfur and sulfate contents of the $\mathrm{AH}$ hot spring. Furthermore, the presence of these genes suggests that strain RA plays a role in the recycling of sulfur within the hot spring. Two cholesterol oxidase genes were also present in strain RA but not in closely related genera. Notably, cholesterol oxidases catalyze the conversion of cholesterol to cholest-4-en-3-one, which has been proposed as a potential drug candidate for treatment of amyotrophic lateral sclerosis (Bordet et al., 2007).

KEGG metabolic pathway analyses indicated that the starch and sucrose metabolism pathways of strain RA are similar to those of Rhodothermus and Salinibacter spp. According to these analyses, strain RA is capable of hydrolyzing starch to maltose, glucose, or trehalose and converting starch to glycogen. Meanwhile, all three genera encode the enzymes (EC 3.2.1.4 and 3.2.1.21) necessary for hydrolysis of cellulose to glucose Figure S1.

Likewise, R. marinus DSM $4252^{\mathrm{T}}$, S. ruber DSM $13855^{\mathrm{T}}$, and strain RA each encode a type I system (TolC), a SecSRP pathway (SecD/F, SecY, SecA, YidC, FstY, Ffh), and a Tat pathway (TatC) for protein secretion. However, while strain RA also carries genes encoding type II (GspD, GspE, GspF) and type VI (VgrG, Hcp, IcmF, DotU, ClpV) secretion systems, virulence factor prediction analyses using the PATRIC database 
TABLE 3 | Genome statistics of strain RA.

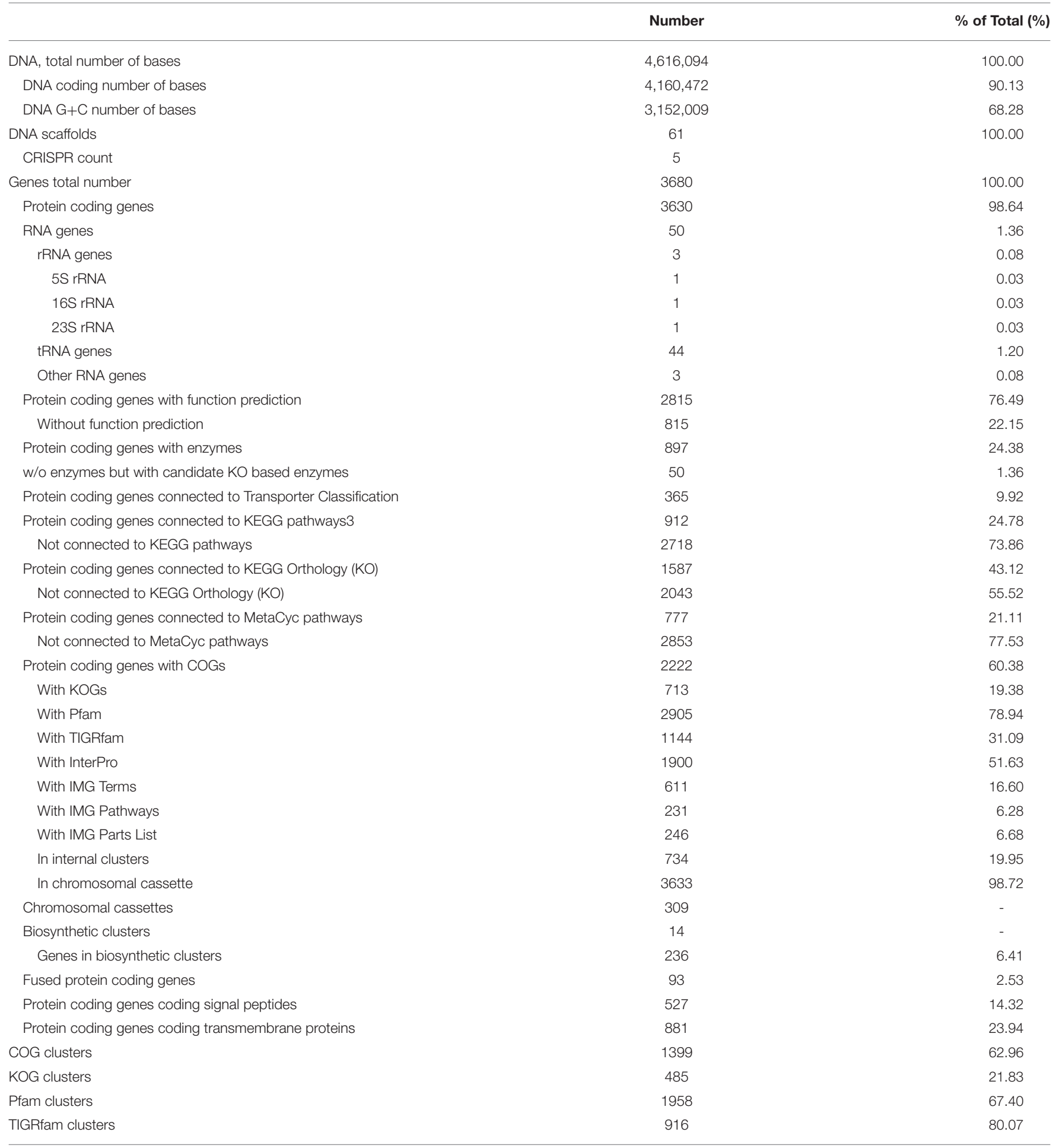

(Wattam et al., 2014), VirulenceFinder 1.5 (Joensen et al., 2014), and ResFinder 2.1 (Zankari et al., 2012) indicated that this strain is likely non-pathogenic.

Certain ABC transporters encoded by strain RA, including those specific for phosphate (PstS, PstA, PstB, PstC), lipoproteins (LolC, LolE, LolD), and iron-siderophores (FhuB, FhuC, FhuD), are potentially produced by $R$. marinus DSM $4252^{\mathrm{T}}$ and S. ruber DSM $13855^{\mathrm{T}}$. In addition, there were multiple transporters that were encoded in the genomes of strain RA and R. marinus DSM $4252^{\mathrm{T}}$ but not in that of $S$. ruber DSM $13855^{\mathrm{T}}$, including transporters for molybdate (ModA, ModB), iron(III; AfuA, AfuB), zinc/manganese/iron (TroA, 


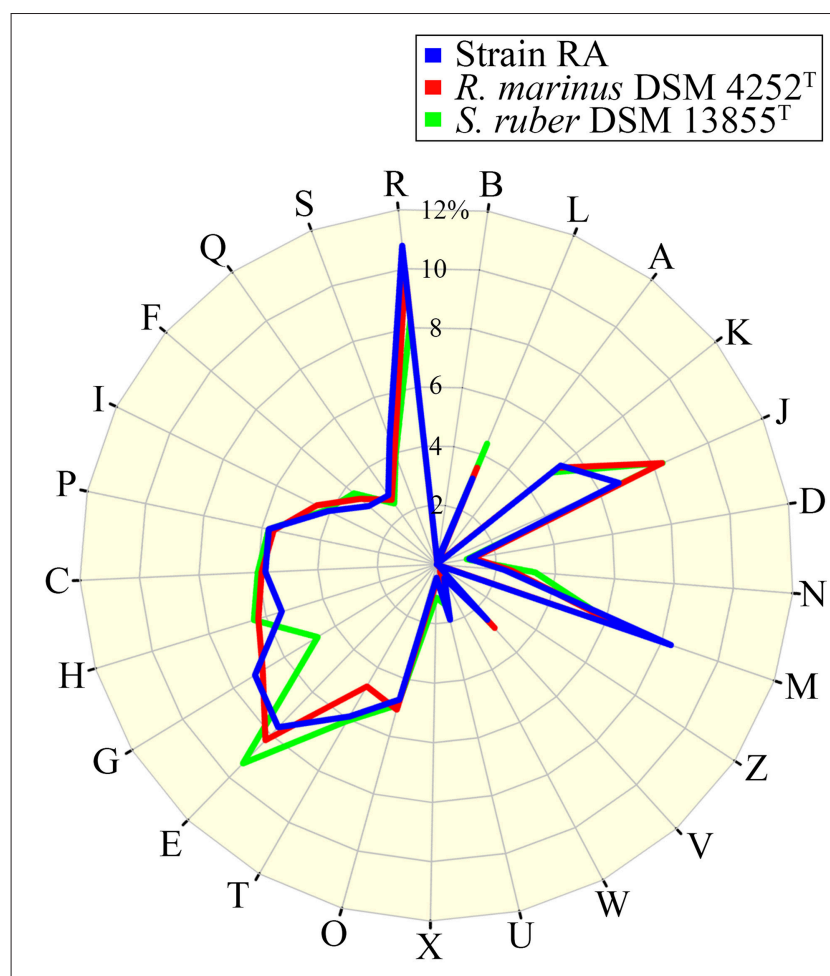

FIGURE 2 | Percentage of CDS involved in COG classifications for strain RA, R. marinus DSM $4252^{\top}$ and S. ruber DSM $13855^{\top}$. B,

Chromatin structure and dynamics; L, replication, recombination, and repair; A, RNA processing and modification; K, transcription; J, translation, ribosomal structure, and biogenesis; D, cell cycle control, cell division, chromosome partitioning; N, cell motility; M, cell wall/membrane/envelope biogenesis; Z, cytoskeleton; $\mathrm{V}$, defense mechanisms; $\mathrm{W}$, extracellular structures; $\mathrm{U}$, intracellular trafficking, secretion, and vesicular transport; $\mathrm{X}$, mobilome, prophages, transposons; O, post-translational modification, protein turnover, chaperones; T, Signal transduction mechanisms; E, amino acid transport and metabolism; G, carbohydrate transport and metabolism; $\mathrm{H}$, coenzyme transport and metabolism; C, energy production and conversion; $\mathrm{P}$, inorganic ion transport and metabolism; I, lipid transport and metabolism; F, nucleotide transport and metabolism; Q, secondary metabolites biosynthesis, transport and catabolism; S, function unknown; and R, general function prediction only (https://figshare.com/s/8a2ccd9f2b7aa439f040).

TroB, TroC, TroD), raffinose/stachyose/melibiose (MsmK), sorbitol/mannitol (SmoK), cellobiose (MsiK), chitobiose (MsiK), arabinooligosaccharide (MsmX), and glucose/mannose (MalK; Table S2). Meanwhile, strain RA also encodes an RbsABC transporter for uptake of ribose/xylose. Lastly, strain RA contains genes encoding unique CusS, CusR, CusB, and CusA proteins that are predicted to play a role in copper and/or silver efflux, which are absent from all currently known Rhodothermus and Salinibacter spp.

\section{Temperature Adaptation Genes of Strain RA}

The average water temperature of the $\mathrm{AH}$ hot spring during sampling was $45^{\circ} \mathrm{C}$; however, in vitro analysis demonstrated that strain $\mathrm{RA}$ is capable of thriving at temperatures up to $60^{\circ} \mathrm{C}$. Meanwhile, analysis of the composition of the spring water detected high levels of $\mathrm{NaCl}$. We therefore endeavored to elucidate the mechanisms by which strain RA withstands thermal and osmotic stresses by characterizing the stress-related genes within the annotated genome.

The linear polyamines putrescine and spermidine have been associated with the thermophilicity of thermophiles (Takahashi and Kakehi, 2010; Goh et al., 2014). Notably, in addition to harboring the genes necessary to synthesize putrescine via $N$ carbamoylputrescine amidase, strain RA appears to be capable of taking up putrescine and spermidine from the environment using the Pot $\mathrm{A}$ and PotC transporters. In contrast, the genes encoding PotA and PotC are not present in the genomes of $R$. marinus DSM $4252^{\mathrm{T}}$ and S. ruber DSM $13855^{\mathrm{T}}$. A unique sequence in strain RA was annotated as a primosomal protein $\mathrm{N}^{\prime}$ (replication factor Y) superfamily II helicase gene, and the corresponding protein sequence exhibited $>58 \%$ sequence identity to PriA helicases deposited in GenBank. Several of these helicases have been proposed to play important roles in the thermostability of certain thermophiles (Goh et al., 2014). As mentioned earlier, the GC content of the strain RA genome is higher than that of most other genomes of Rhodothermaceae. In some cases, high genome and tRNA GC\% levels are associated with increased optimal growth temperatures (Trivedi et al., 2005). Yet, the average tRNA GC content $(61.4 \%)$ of strain RA is slightly lower than that of the rest of the genomes (68.3\%). Additionally, the strain RA genome contains CDS that exhibit sequence similarity to genes encoding chaperones (DnaJ, DnaK, HtrA, metal chaperone) and the known heat shock proteins GroES and GroEL (HSP-60 family co-chaperones), and it contains three copies of the gene encoding the cold shock protein CspA. These CspA proteins exhibited the highest level of sequence identity to counterparts from $R$. marinus DSM $4252^{\mathrm{T}}(67,78$, and $80 \%$, respectively).

\section{Osmotic Stress Adaptation Genes of Strain RA}

We detected several genes encoding proteins involved in adaptation to osmotic stress within the strain RA genome, including $\mathrm{Na}^{+} / \mathrm{H}^{+}$antiporters, a sodium/solute symporter, and a sodium/glutamate symporter (Table S3). Moreover, we detected three separate trehalose synthase genes (EC 5.4.99.16), which exhibited $64-65 \%$ identity to genes present in S. longa DSM $21114^{\mathrm{T}}$ and $S$. ruber DSM $13855^{\mathrm{T}}$, while similar genes were absent from the $R$. marinus DSM $4252^{\mathrm{T}}$ genome. Strain RA also harbors a gene predicted to encode malto-oligosyltrehalose trehalohydrolase (EC 5.3.2.141) that is 58\% similar to a gene present in S. ruber DSM $13855^{\mathrm{T}}$. It also has a maltooligosyltrehalose synthase (EC 5.4.99.15) gene that exhibits 58\% sequence identity to a CDS present in Truepera radiovictrix but has no homologs in the genomes of S. longa DSM $21114^{\mathrm{T}}$, S. ruber DSM $13855^{\mathrm{T}}$, and R. marinus DSM $4252^{\mathrm{T}}$. In addition, strain RA is predicted to be capable of biosynthesizing the osmoprotectant choline via a choline-sulfatase (EC 3.1.6.6). However, unlike S. ruber DSM $13855^{\mathrm{T}}$, both strain RA and R. marinus DSM $4252^{\mathrm{T}}$ lack the genes encoding the osmoprotectant-associated transporters ProX, ProW, ProV, OpuBC, OpuBB, and OpuBA. Lastly, strain RA encodes the potassium uptake proteins TrkA 
and $\operatorname{TrkH}$, the osmotically inducible protein $\mathrm{C}$, and the $\mathrm{K}^{+}$ channel histidine kinase $\mathrm{KdpD}$ but lacks genes encoding a glycine betaine transporter or proteins involved in ectoine transport/synthesis.

\section{CONCLUSIONS}

In this report, we have described the genome of strain RA, which was isolated from a saline hot spring in Malaysia. The draft genome of strain RA comprises 4,616,094 bp with a mean GC content of $68.3 \%$. It contains 91 contigs with an N50 contig length of $152,113 \mathrm{bp}$. This genome is predicted to include 3630 protein-coding genes. At a $60 \%$ identity cutoff, a low percentage of these protein-coding genes are similar to genes in the phylum Bacteroidetes. The results of $16 \mathrm{~S}$ rRNA gene sequencing, ANI-value and genome comparisons clearly indicate that this strain exhibits many differences from known genera of Rhodothermaceae. In the NCBI taxonomy database, the lineage for strain RA is classified as Bacteria; FCB group; Bacteroidetes/Chlorobi group; Bacteroidetes; Bacteroidetes Order II. Incertae sedis; Rhodothermaceae; unclassified Rhodothermaceae. In the near future, chemotaxonomic and phenotypic characterization of strain RA will be performed to further compare this strain with

\section{REFERENCES}

Alfredsson, G. A., Kristjansson, J. K., Hjörleifsdottir, S., and Stetter, K. O. (1988). Rhodothermus marinus, gen. nov., sp. nov., a thermophilic, halophilic bacterium from submarine hot springs in Iceland. Microbiology 134, 299-306. doi: 10.1099/00221287-134-2-299

Antón, J., Oren, A., Benlloch, S., Rodríguez-Valera, F., Amann, R., and RossellóMora, R. (2002). Salinibacter ruber gen. nov., sp. nov., a novel, extremely halophilic member of the bacteria from saltern crystallizer ponds. Int. J. Syst. Evol. Microbiol. 52, 485-491. doi: 10.1099/00207713-52-2-485

Besemer, J., and Borodovsky, M. (2005). GeneMark: web software for gene finding in prokaryotes, eukaryotes and viruses. Nucleic Acids Res. 33, W451-W454. doi: 10.1093/nar/gki487

Blin, K., Medema, M. H., Kazempour, D., Fischbach, M. A., Breitling, R., Takano, E., et al. (2013). antiSMASH 2.0-a versatile platform for genome mining of secondary metabolite producers. Nucleic Acids Res. 41, W204-W212. doi: 10.1093/nar/gkt449

Blücher, A., Karlsson, E. N., and Holst, O. (2000). Substrate-dependent production and some properties of a thermostable, $\alpha$-galactosidase from Rhodothermus marinus. Biotechnol. Lett. 22, 663-669. doi: 10.1023/A:1005627501609

Bordet, T., Buisson, B., Michaud, M., Drouot, C., Galéa, P., Delaage, P., et al. (2007). Identification and characterization of cholest-4-en-3-one, oxime (TRO19622), a novel drug candidate for amyotrophic lateral sclerosis. J. Pharmacol. Exp. Ther. 322, 709-720. doi: 10.1124/jpet.107.123000

Chai, Y. Y., Kahar, U. M., Salleh, M. M., Illias, R. M., and Goh, K. M. (2012). Isolation and characterization of pullulan-degrading Anoxybacillus species isolated from Malaysian hot springs. Environ. Technol. 33, 1231-1238. doi: 10.1080/09593330.2011.618935

Cowan, S. T., and Steel, K. J. (1965). Manual for the Identification of Medical Bacteria. London: Cambridge University Press.

Goh, K. M., Gan, H. M., Chan, K. G., Chan, G. F., Shahar, S., Chong, C. S., et al. (2014). Analysis of Anoxybacillus genomes from the aspects of lifestyle adaptations, prophage diversity, and carbohydrate metabolism. PLoS ONE 9:e90549. doi: 10.1371/journal.pone.0090549

Gomes, I., Gomes, J., and Steiner, W. (2003). Highly thermostable amylase and pullulanase of the extreme thermophilic eubacterium Rhodothermus marinus: other related type strains from the family Rhodothermaceae, and names for the genus and species will be proposed.

\section{AUTHOR CONTRIBUTIONS}

$\mathrm{KG}$ and $\mathrm{KC}$ designed the experiments and wrote manuscript; SL, $\mathrm{KL}, \mathrm{CC}, \mathrm{RE}, \mathrm{MS}$, and TA performed biochemical and sequencing experiments, and analyzed the genetic content of the bacterium.

\section{ACKNOWLEDGMENTS}

This work was supported by the University of Malaya via High Impact Research Grants [UM.C/625/1/HIR/MOHE/CHAN/01 (Grant No. A-000001-50001) and UM.C/625/1/HIR/MOHE/CHAN/14/1 (Grant No. H-50001-A000027)] awarded to KC. KG is grateful for funding received from Universiti Teknologi Malaysia GUP (Grant 09H98).

\section{SUPPLEMENTARY MATERIAL}

The Supplementary Material for this article can be found online at: http://journal.frontiersin.org/article/10.3389/fmicb. 2016.01109 production and partial characterization. Bioresour. Technol. 90, 207-214. doi: 10.1016/S0960-8524(03)00110-X

Gomes, J., Gomes, I., Terler, K., Gubala, N., Ditzelmüller, G., and Steiner, W. (2000). Optimisation of culture medium and conditions for $\alpha$-Larabinofuranosidase production by the extreme thermophilic eubacterium Rhodothermus marinus. Enzyme Microb. Technol. 27, 414-422. doi: 10.1016/S0141-0229(00)00229-5

Hobel, C. F., Hreggvidsson, G. O., Marteinsson, V. T., Bahrani-Mougeot, F., Einarsson, J. M., and Kristjansson, J. K. (2005). Cloning, expression, and characterization of a highly thermostable family 18 chitinase from Rhodothermus marinus. Extremophiles 9, 53-64. doi: 10.1007/s00792-0040422-3

Joensen, K. G., Scheutz, F., Lund, O., Hasman, H., Kaas, R. S., Nielsen, E. M., et al. (2014). Real-time whole-genome sequencing for routine typing, surveillance, and outbreak detection of verotoxigenic Escherichia coli. J. Clin. Microbiol. 52, 1501-1510. doi: 10.1128/JCM.03617-13

Kim, O.-S., Cho, Y.-J., Lee, K., Yoon, S.-H., Kim, M., Na, H., et al. (2012). Introducing EzTaxon-e: a prokaryotic 16S rRNA gene sequence database with phylotypes that represent uncultured species. Int. J. Syst. Evol. Microbiol. 62, 716-721. doi: 10.1099/ijs.0.038075-0

Lane, D. J. (1991). "16S/23S rRNA sequencing," in Nucleic Acid Techniques in Bacterial Systematics, eds E. Stackebrandt and M. Goodfellow (Chichester: Wiley), 115-117.

Makhdoumi-Kakhki, A., Amoozegar, M. A., and Ventosa, A. (2012). Salinibacter iranicus sp. nov. and Salinibacter luteus sp. nov., isolated from a salt lake, and emended descriptions of the genus Salinibacter and of Salinibacter ruber. Int. J. Syst. Evol. Microbiol. 62, 1521-1527. doi: 10.1099/ijs.0.031971-0

Mao, C., Abraham, D., Wattam, A. R., Wilson, M. J., Shukla, M., Yoo, H. S., et al. (2015). Curation, integration and visualization of bacterial virulence factors in PATRIC. Bioinformatics 31, 252-258. doi: 10.1093/bioinformatics/btu631

Markowitz, V. M., Mavromatis, K., Ivanova, N. N., Chen, I.-M. A., Chu, K., and Kyrpides, N. C. (2009). IMG ER: a system for microbial genome annotation expert review and curation. Bioinformatics 25, 2271-2278. doi: 10.1093/bioinformatics/btp393

Marteinsson, V. T., Bjornsdottir, S. H., Bienvenu, N., Kristiánsson, J. K., and Birrien, J. L. (2010). Rhodothermus profundi sp. nov., a thermophilic bacterium 
isolated from a deep-sea hydrothermal vent in the Pacific Ocean. Int. J. Syst. Evol. Microbiol. 60, 2729-2734. doi: 10.1099/ijs.0.012724-0

Mongodin, E. F., Nelson, K., Daugherty, S., Deboy, R., Wister, J., Khouri, H., et al. (2005). The genome of Salinibacter ruber: convergence and gene exchange among hyperhalophilic bacteria and archaea. Proc. Natl. Acad. Sci. U.S.A. 102, 18147-18152. doi: 10.1073/pnas.0509073102

Nolan, M., Tindall, B. J., Pomrenke, H., Lapidus, A., Copeland, A., Glavina Del Rio, T., et al. (2009). Complete genome sequence of Rhodothermus marinus type strain $\left(\mathrm{R}-10^{\mathrm{T}}\right)$. Stand. Genomic Sci. 1, 283-291. doi: 10.4056/sigs.46736

Ojima, T., Saburi, W., Sato, H., Yamamoto, T., Mori, H., and Matsui, H. (2011). Biochemical characterization of a thermophilic cellobiose 2-epimerase from a thermohalophilic bacterium, Rhodothermus marinus JCM9785. Biosci. Biotechnol. Biochem. 75, 2162-2168. doi: 10.1271/bbb.110456

Okano, H., Ozaki, M., Kanaya, E., Kim, J.-J., Angkawidjaja, C., Koga, Y., et al. (2014). Structure and stability of metagenome-derived glycoside hydrolase family 12 cellulase (LC-CelA) a homolog of Cel12A from Rhodothermus marinus. FEBS Open Bio 4, 936-946. doi: 10.1016/j.fob.2014.10.013

Oren, A. (2013). Salinibacter: an extremely halophilic bacterium with archaeal properties. FEMS Microbiol. Lett. 342, 1-9. doi: 10.1111/1574-6968.12094

Oren, A., Abu-Ghosh, S., Argov, T., Kara-Ivanov, E., Shitrit, D., Volpert, A., et al. (2016). Expression and functioning of retinal-based proton pumps in a saltern crystallizer brine. Extremophiles 20,69-77. doi: 10.1007/s00792-015-0798-2

Park, S., Akira, Y., and Kogure, K. (2014). "The family Rhodothermaceae," in The Prokaryotes, eds. E. Rosenberg, E. F. Delong, S. Lory, E. Stackebrandt, and F. Thompson (Berlin, Heidelberg: Springer-Verlag), 849-856.

Park, S., Song, J., Yoshizawa, S., Choi, A., Cho, J. C., and Kogure, K. (2013). Rubrivirga marina gen. nov., sp. nov., a member of the family Rhodothermaceae isolated from deep seawater. Int. J. Syst. Evol. Microbiol. 63, 2229-2233. doi: 10.1099/ijs.0.046318-0

Park, S., Yoshizawa, S., Kogure, K., and Yokota, A. (2011). Rubricoccus marinus gen. nov., sp. nov., of the family "Rhodothermaceae", isolated from seawater. Int. J. Syst. Evol. Microbiol. 61, 2069-2072. doi: 10.1099/ijs.0.026294-0

Peña, A., Teeling, H., Huerta-Cepas, J., Santos, F., Yarza, P., Brito-Echeverría, J., et al. (2010). Fine-scale evolution: genomic, phenotypic and ecological differentiation in two coexisting Salinibacter ruber strains. ISME J. 4, 882-895. doi: 10.1038/ismej.2010.6

Peña, A., Valens, M., Santos, F., Buczolits, S., Antón, J., Kämpfer, P., et al. (2005). Intraspecific comparative analysis of the species Salinibacter ruber. Extremophiles 9, 151-161. doi: 10.1007/s00792-005-0430-y

Rosselló-Mora, R., Lucio, M., Peña, A., Brito-Echeverría, J., López-López, A., Valens-Vadell, M., et al. (2008). Metabolic evidence for biogeographic isolation of the extremophilic bacterium Salinibacter ruber. ISME J. 2, 242-253. doi: 10.1038/ismej.2007.93

Sako, Y., Takai, K., Ishida, Y., Uchida, A., and Katayama, Y. (1996). Rhodothermus obamensis sp. nov., a modern lineage of extremely thermophilic marine bacteria. Int. J. Syst. Evol. Microbiol. 46, 1099-1104. doi: 10.1099/00207713-464-1099

Schaeffer, A. B., and Fulton, M. D. (1933). A simplified method of staining endospores. Science 77, 194-194. doi: 10.1126/science.77.1990.194

Silva, Z., Horta, C., Da Costa, M. S., Chung, A. P., and Rainey, F. A. (2000), Polyphasic evidence for the reclassification of Rhodothermus obamensis Sako et al. 1996 as a member of the species Rhodothermus marinus Alfredsson et al. 1988. Int. J. Syst. Evol. Microbiol. 50, 1457-1461. doi: 10.1099/00207713-50-41457

Singh, P., Anand, A., and Kumar, V. (2014). Recent developments in biological activities of chalcones: a mini review. Eur. J. Med. Chem. 85, 758-777. doi: 10.1016/j.jejmech.2014.08.033

Takahashi, T., and Kakehi, J. I. (2010). Polyamines: ubiquitous polycations with unique roles in growth and stress responses. Ann. Bot. 105, 1-6. doi: 10.1093/aob/mcp259

Tamura, K., Stecher, G., Peterson, D., Filipski, A., and Kumar, S. (2013). MEGA6: Molecular Evolutionary Genetics Analysis version 6.0. Mol. Biol. Evol. 30, 2725-2729. doi: 10.1093/molbev/mst197

Trivedi, S., Rao, S. R., and Gehlot, H. S. (2005). Nucleic acid stability in thermophilic prokaryotes: a review. J. Cell Mol. Biol. 4, 61-69.

Vaisman, N., and Oren, A. (2009). Salisaeta longa gen. nov., sp. nov., a red, halophilic member of the Bacteroidetes. Int. J. Syst. Evol. Microbiol. 59, 2571-2574. doi: 10.1099/ijs.0.010892-0

Wattam, A. R., Abraham, D., Dalay, O., Disz, T. L., Driscoll, T., Gabbard, J. L., et al. (2014). PATRIC, the bacterial bioinformatics database and analysis resource. Nucleic Acids Res. 42, D581-D591. doi: 10.1093/nar/gkt1099

Xia, J., Zhou, Y. X., Zhao, L. H., Chen, G. J., and Du, Z. J. (2015). Longimonas halophila gen. nov., sp. nov., isolated from a marine solar saltern. Int. J. Syst. Evol. Microbiol. 65, 2272-2276. doi: 10.1099/ijs.0.000247

Zankari, E., Hasman, H., Cosentino, S., Vestergaard, M., Rasmussen, S., Lund, O., et al. (2012). Identification of acquired antimicrobial resistance genes. J. Antimicrob. Chemother. 67, 2640-2644. doi: 10.1093/jac/ dks261

Conflict of Interest Statement: The authors declare that the research was conducted in the absence of any commercial or financial relationships that could be construed as a potential conflict of interest.

Copyright (๑) 2016 Goh, Chan, Lim, Liew, Chan, Shamsir, Ee and Adrian. This is an open-access article distributed under the terms of the Creative Commons Attribution License (CC BY). The use, distribution or reproduction in other forums is permitted, provided the original author(s) or licensor are credited and that the original publication in this journal is cited, in accordance with accepted academic practice. No use, distribution or reproduction is permitted which does not comply with these terms. 